\title{
ANÁLISIS EXPLORATORIO DE LA APERTURA COMERCIAL DEL ECUADOR FRENTE A PERÚ Y COLOMBIA
}

\author{
EXPLORATORY ANALYSIS ABOUT ECUADORIAN COMMERCIAL \\ OPENING WITH RESPECT TO PERU AND COLOMBIA
}

\section{Resumen}

El presente trabajo pretende comparar el nivel de apertura comercial del Ecuador con respecto a Perú y Colombia, por medio de variables determinantes provenientes de las estadísticas públicas y bibliografía concerniente al tema, con el fin de ofrecer una respuesta del por qué Ecuador se percibe como un país proteccionista y con un menor desempeño comercial. Se trata de una nota exploratoria centrada en las áreas de la política comercial, comercio exterior y relaciones internacionales, de orden descriptiva por medio de indagación bibliográfica y análisis estadístico; complementado con un análisis de percepción por medio de entrevistas dirigidas a informantes clave del sector público, privado y la academia de Ecuador, Perú y Colombia.

Palabras clave: Ecuador, Perú, Colombia, Comercio Exterior, Política Comercial.

\begin{abstract}
This paper aims to compare the level of trade openness of Ecuador with respect to Peru and Colombia by means of determining variables from public statistics and bibliography concerning the subject, in order to offer an answer as to why Ecuador is perceived as a protectionist country and with a lower commercial performance. This is an exploratory research focused on the areas of trade policy, foreign trade and international relations. It is a descriptive research made by means of bibliographic inquiry and statistical analysis, complemented with an analysis of perception through interviews directed to key informants from the public, private sector and academia.
\end{abstract}

Keywords: Ecuador, Peru, Colombia, International Trade, Trade Policy. 


\section{Introducción}

Actualmente la comunicación ha traspasado las fronteras entre los países y las relaciones comerciales internacionales se han intensificado en los últimos años (Panezi, 2016, pág. 3). Para Latinoamérica este incremento de la apertura comercial empieza con la proliferación de acuerdos comerciales desde el año 2000 , en donde importantes factores como el estancamiento de la Ronda de Doha de la Organización Mundial de Comercio (OMC), el crecimiento económico de China y el "boom de las materias primas", encaminaron a la Región hacia el aperturismo de sus economías, por lo que, la ratificación de acuerdos comerciales con socios estratégicos, ha sido clave (CEPAL, 2015, págs. 42-60).

Asimismo, la falta de pericia para poder materializar una integración política, económica y social por parte de Latinoamérica ha dado como resultado el estancamiento de importantes bloques como: la Comunidad Andina de Naciones (CAN), el Mercado Común del Sur (MERCOSUR) y la Unión de Naciones Suramericanas (UNASUR), en donde varios países de esta región han buscado nuevas opciones en mercados, más diversificados y con mayores oportunidades de competitividad (Herrera, 2015, págs. 169-180).

Dentro de este contexto de apertura comercial resalta la importancia de la política comercial bilateral, la misma que está siendo muy utilizada en Latinoamérica, en donde el Tratado de Libre Comercio (TLC) de Estados Unidos con Colombia y con Perú, el TLC de China con Perú y con Costa Rica, el TLC entre Panamá y Chile, y el Acuerdo de Asociación de la Unión Europea con Perú y con Colombia, son ejemplos claros de este nivel de integración. Cabe mencionar que recién en el año 2014 el Ecuador anuncia las negociaciones de un Acuerdo Multipartes con la Unión Europea, siendo el acuerdo más representativo de este país (BID, 2016, págs. 10-15).

Ahora bien, el problema se centra en que dentro de Latinoamérica el Ecuador no resalta como un país que posea una política comercial aperturista ni que haya utilizado a la política comercial bilateral como una herramienta consolidada para poder competir con sus vecinos más próximos: Perú y Colombia, países que han tenido un mayor desarrollo y apertura comercial, llegando a mercados y atrayendo inversiones que, para Ecuador se encuentran aún muy distantes (Montaño, 2010, págs. 89-92).

Bajo este contexto, en el presente trabajo exploratorio se realiza una comparación del nivel de apertura comercial del Ecuador con respecto a Perú y Colombia por medio de la construcción de una matriz con variables determinantes como: acuerdos comerciales vigentes, arancel consolidado, riesgo país, índice de libertad económica, exportaciones totales, e inversión extranjera directa (IED).

A continuación se realiza un análisis de percepción de la política comercial ecuatoriana por medio de entrevistas estructuradas dirigidas a informantes clave del sector público, privado y la academia de Ecuador, Perú y Colombia.

Con toda la información encontrada se procede a responder con una alternativa del por qué el Ecuador posee un desempeño comercial inferior al de Perú y Colombia, posicionándose como un país proteccionista.

\section{Revisión de la literatura}

Dentro de la literatura pertinente existen diferentes publicaciones como la de Corbo (1985), la 
cual señala que las barreras arancelarias y no arancelarias a largo plazo son más perjudiciales que beneficiosas para los países que las usan, ya que incurre en altos costos de producción y consumo. El autor asegura que la restricción a las importaciones a largo plazo se enfoca más en el capital que en el trabajo, lo cual se convierte en un conflicto sobre todo para países en desarrollo, ya que los países que cuentan con abundante capital humano absorben mucho más empleo al producir para el mercado externo, que al producir sustitutos de las importaciones.

Berg \& Krueguer (2002) destacan en su publicación que factores como el incremento del ingreso per cápita, la reducción de la pobreza, el aumento del comercio internacional y la certidumbre jurídica para la atracción del capital privado van ligados cualitativa y cuantitativamente a la apertura comercial, y que dichos factores son más representativos en países que han optado por el aperturismo, a diferencia de los países proteccionistas que tienden a un desarrollo más estático que dinámico, tendiendo a mostrar una imagen menos atractiva para la atracción de capitales externos.

Asimismo, Loko \& Diouf (2009) como Jaumotte \& Spatafora (2007) indican que una política comercial debe ser encaminada hacia la apertura de la misma, ya que por medio del aperturismo comercial se obtiene mayor nivel de productividad a largo plazo, en donde factores como el nivel de exportaciones y la atracción de inversión extranjera directa, son determinantes en sus estudios. Además, puntualizan que la exportación de bienes y servicios puede proporcionar mayores ingresos para los países en desarrollo, incrementando la recaudación pública, equiparando la distribución de la renta y aumentando el empleo, incluyendo empleos mejor remunerados y diversificados hacia los trabajadores jóvenes.

De igual manera, el estudio publicado por Durán, Finot, \& LaFleur (2010) señala la importancia de la apertura comercial para los países en desarrollo con mercados internos reducidos y economías emergentes, ya que con la ratificación de acuerdos comerciales bilaterales y con la ejecución de adecuadas políticas públicas, los gobiernos pueden desarrollar herramientas consolidadas que contribuyan en la reducción de la pobreza. En este mismo trabajo se hace una recomendación a que se apliquen estudios comparativos con países que tienen una política comercial proteccionista tomando en cuenta el caso de Ecuador y Bolivia.

Bayne \& Woolcock (2011), en su publicación hacen mención a que la política comercial de un país no puede ser explicada únicamente por factores económicos, sino que, al momento de crearla prevalezca el compromiso de un gobierno por cumplir con sus propuestas, programas de trabajo y metas internas (distribución del ingreso, empleo). Es por ello que la política comercial puede ser vista como una herramienta de consolidación de poder en un Estado, pues se podrían llevar a cabo alianzas comerciales para dañar la economía de un país rival.

\section{Política comercial de Ecuador}

La política comercial de Ecuador está regulada por el Código Orgánico de la Producción, Comercio e Inversiones (COPCI), legislación vigente desde diciembre del año 2010 bajo el gobierno de Rafael Correa. El COPCI tiene por objetivo, "regular el proceso productivo en las etapas de producción, distribución, intercambio, comercio, consumo, manejo de externalidades e inversiones productivas orientadas a la realización del Buen Vivir" (COPCl, 2010).

De acuerdo con la Ley, la política comercial ecuatoriana busca incrementar las exportaciones no petroleras con valor agregado, atraer inversión extranjera directa a través de incentivos a la 
inversión, delimitar sectores prioritarios, descentralizar la economía, sustituir las importaciones con producción nacional de alta calidad, desarrollar zonas especiales de desarrollo económico (Zedes), facilitar el comercio exterior, etc.

Sin embargo, estos objetivos no se han logrado materializar aún, ya que persiste una alta dependencia del petróleo ( $36 \%$ de las exportaciones totales) y las exportaciones de manufacturas con bajo, medio y alto nivel de valor agregado no han tenido el impacto esperado $(13,8 \%$ de las exportaciones totales) (Trade Map, 2018).

Por otro lado, la política comercial ecuatoriana ha sido examinada por uno de los órganos de la Organización Mundial de Comercio, Ilamado Trade Policy Review (TPR), por sus siglas en inglés o también llamado Examen de Política Comercial, este procedimiento fue realizado en el año 2011 siendo la segunda vez que se ha hecho un examen a la política comercial de este país desde el año 2005.

Dentro de este examen aplicado a la política comercial ecuatoriana, la OMC destaca el trabajo realizado por el Estado al implementar el COPCI, teniendo como resultado una mayor herramienta para consolidar el cambio de la matriz productiva y sobre todo, mostrando al mundo que Ecuador está consolidando sus relaciones económicas internacionales, incentivando las exportaciones y otorgando mayor certidumbre al inversionista extranjero, el mismo que puede hacer uso de los beneficios que el Código otorga a las nuevas inversiones tales como: Exoneraciones al Impuesto a la Renta, al Impuesto a la Salida de Divisas, incentivos para empresas medianas, etc.

De igual manera, Ecuador pertenece al grupo de los países de "Reciente Ingreso" a la OMC en el año 1996 y al grupo de "Economías Pequeñas y Vulnerables" por su representación del 0,098\% en el comercio mundial. Como miembro de la organización, la OMC destaca la activa participación de Ecuador en las negociaciones de Facilitación del Comercio y la Ronda de Negociaciones de Doha, la misma que busca mayores beneficios para los países en desarrollo como: mayor acceso a los mercados agrícolas y no agrícolas, eliminación de la progresividad arancelaria, las subvenciones causantes de distorsión, etc. Sin embargo, las negociaciones de Doha siguen estancadas desde el año 2001.

Por otro lado, en lo que se refiere a la participación en procesos plurilaterales, el Ecuador se ve como un país con cierta resistencia a la apertura comercial ya que no pertenece a ningún acuerdo plurilateral de la OMC como: el Acuerdo sobre Tecnología de la Información y el Acuerdo sobre Contratación Pública, entre otros.

En lo que se refiere a política comercial bilateral, Ecuador tiene un mayor acercamiento a Bahamas, Yemen, Argelia, Bosnia-Herzegovina, Líbano, Irán, Libia, Montenegro y Bielorrusia; sin embargo, estos países no representan mercados tan importantes como son la Unión Europea, y Estados Unidos, con los cuales, la OMC recomienda que Ecuador debe negociar acuerdos comerciales para desarrollar e incrementar el acceso a mercados dado que, son los principales destinos de sus exportaciones (OMC, 2012).

En el ámbito de los acuerdos comerciales, Ecuador puntualiza que busca una liberalización de las medidas arancelarias y no arancelarias con mayor imparcialidad para las economías de los Estados parte, con el objetivo de disminuir las asimetrías existentes. Con respecto a la complementariedad, las negociaciones ecuatorianas buscan además de facilitar el comercio bilateral, producir y sostener en el tiempo a las cadenas globales de valor en sectores donde las partes pueden ser complementarias, no suplementarias, beneficiándose todos los involucrados de forma plena y mutua. 
Con esto se resalta la intención del Ecuador en buscar negociaciones horizontales y complementarias, con el fin de diferenciar entre países desarrollados y países en desarrollo, lo cual posiciona a Ecuador como un país que ejecutará una apertura comercial con socios que coincidan con lo mencionado anteriormente (OMC, 2012).

En la actualidad, la política comercial del Ecuador se ha ido consolidando de una manera más pragmática que idealista para aprovechar de mejor manera las oportunidades comerciales y de inversión que traen consigo los acuerdos comerciales. Dentro de este contexto sobresale el Acuerdo Multipartes entre Ecuador y la Unión Europea, el mismo que está vigente desde enero del 2017 y que cumple con la naturaleza de acuerdo comercial que el Ecuador pretende conseguir, en donde la cooperación y la diferenciación entre fortalezas y oportunidades "país desarrollado - país en desarrollo", puedan construir una plataforma en la que los productos ecuatorianos compitan de mejor manera en los mercados internacionales y al mismo tiempo, sea posible proteger los productos con mayor sensibilidad frente al aumento de las importaciones.

Asimismo y pensando en el mercado europeo como un socio estratégico para el Ecuador, este país inició a mediados del 2016 las negociaciones de un acuerdo de asociación económica, con la Asociación Europea de Libre Comercio (EFTA) conformada por: Noruega, Suiza, Islandia y Liechtenstein, acuerdo que fue firmado en junio del 2018 y busca la internacionalización y empoderamiento de los productos ecuatorianos en mercados donde no tenía mayor competitividad (Ministerio de Comercio Exterior e Inversiones. Ecuador, 2017).

Dentro de estos nuevos acuerdos suscritos por Ecuador, tanto con la UE como con el EFTA, el Ecuador tiene un potencial exportador ligado a los recursos naturales y manufacturas con bajo valor agregado como: banano, camarón, flores, chocolate, artesanías, etc., mientras que el mercado europeo se enfoca en la exportación de servicios y manufacturas con alto valor agregado como: medicinas, maquinaria industrial, automóviles, etc.

Con base a lo expuesto anteriormente, es pertinente buscar la razón por la cual Ecuador tiene aún un desempeño comercial inferior al que manejan sus vecinos más próximos, Perú y Colombia, pese a los esfuerzos que ha destinado este país para desarrollar su política comercial.

\section{Materiales y Métodos}

Para comparar el nivel de apertura comercial del Ecuador con respecto a Perú y Colombia y así ofrecer una alternativa de respuesta del por qué Ecuador se percibe como un país proteccionista y con un menor desempeño comercial, se realiza una nota exploratoria de orden descriptiva por medio de indagación bibliográfica y análisis estadístico, complementado con un análisis de percepción por medio de entrevistas dirigidas a informantes clave de Ecuador, Perú y Colombia.

El análisis de percepción está compuesto por cinco entrevistas estructuradas ${ }^{2}$, ya que de esa manera se puede obtener la información necesaria con respecto a la experiencia laboral y académica de informantes clave pertenecientes al sector público, privado y la academia de los tres países objeto de análisis.

Asimismo, se diseña un cuestionario con cuatro preguntas todas referidas al estudio de caso y

2 Entrevista Estructurada: Es aquellas donde el entrevistador prepara un solo cuestionario para todos los entrevistados, de esa manera la información obtenida puede ser analizada de una manera objetiva y estandarizada (Lifeder, 2018). 
a la pregunta planteada, el mismo que fue respondido vía correo electrónico y se lo presenta a continuación:

1. ¿Cuál es su percepción de la política comercial ecuatoriana?

2. ¿Por qué cree usted que las exportaciones de Ecuador son inferiores a las exportaciones de Perú y Colombia?

3. ¿Qué opina de la apertura comercial?

4. ¿Cree usted que los acuerdos comerciales que mantienen Perú y Colombia con varios socios estratégicos (EEUU, Corea, Japón, etc.) sean determinantes para su mayor posicionamiento frente a Ecuador?

Durante este proceso se realizaron cinco entrevistas dirigidas a:

- Las instituciones del sector público ecuatoriano a cargo del comercio exterior.

- Una institución sector privado ecuatoriano que participa y promueve el comercio exterior.

- Una profesional ecuatoriana que se dedica a la negociación internacional y comercio, y que reside en Colombia.

- Dos académicos y empresarios peruanos que conocen y trabajan en el mercado ecuatoriano.

Para la elección de los informantes se toma en cuenta si su experiencia laboral y académica tiene relación con el tema, además se asegura que cuenten con conocimiento de la economía y política del Ecuador, de esa manera se complementa la percepción.

Además, es pertinente mencionar, que para el caso de los informantes del Ecuador se realiza un acercamiento con el sector público y privado, con el objetivo de conocer y contrastar sus percepciones.

Dentro del análisis, se construye una matriz en la que se puede apreciar puntuales diferencias y semejanzas en la política comercial de Ecuador, Colombia y Perú de acuerdo a las siguientes variables al año 2017:

Acuerdos comerciales vigentes: Es el número de acuerdos comerciales en vigor que tiene cada país dentro del análisis.

Arancel consolidado: El arancel consolidado es el nivel máximo de arancel, Nación Más Favorecida NMF, que un país puede aplicar para una línea de producto determinada, el mismo que fue negociado en el marco de los acuerdos de la Organización Mundial del Comercio.

Riesgo país: Hace referencia a la probabilidad de que un país, emisor de deuda, sea incapaz de responder a sus compromisos de pago de deuda, en capital e intereses, en los términos acordados. Siendo una variable determinante para la atracción de IED.

Índice de libertad económica: Es la libertad que tienen los ciudadanos de un Estado para generar riqueza; mientras más alto sea el índice, mayor libertad económica presentan.

Exportaciones totales: Hace referencia a las exportaciones como porcentaje sobre el PIB.

Inversión extranjera directa: Es el monto anual de capitales extranjeros colocados a largo plazo en un país. 
La importancia de este análisis nace por la necesidad de entender que las variables mencionadas anteriormente influyen directamente en la política comercial de un país y cómo este puede ser percibido por la comunidad internacional.

Trabajos realizados anteriormente por CEPAL (2008), CEPAL (2011) y Torres \& Gilles (2013), destacan la importancia de estas variables como: nivel de exportaciones, medidas arancelarias, integración comercial, libertad económica, etc., con el fin de poder analizar al país objeto de estudio en áreas como política comercial y comercio internacional. Ahora bien, dentro del presente trabajo se ha tomado como punto referencial el caso de Ecuador ya que si bien existen estudios a nivel de Latinoamérica, consta la necesidad de estudiar el nivel de apertura de la política comercial ecuatoriana en este caso haciendo una comparación con sus vecinos más próximos, Perú y Colombia.

\section{Resultados y Discusión}

Tabla 1. Determinantes de apertura comercial de Ecuador, Colombia y Perú, año 2017

\begin{tabular}{|l|l|l|l|l|l|l|}
\hline País & $\begin{array}{l}\text { Acuerdos } \\
\text { Comerciales } \\
\text { Vigentes }\end{array}$ & $\begin{array}{l}\text { Arancel } \\
\text { Consolidado }\end{array}$ & Riesgo País & $\begin{array}{l}\text { Índice de } \\
\text { Libertad } \\
\text { Económica }\end{array}$ & $\begin{array}{l}\text { Exportaciones } \\
\text { Totales en } \\
\text { miles USD }\end{array}$ & $\begin{array}{l}\text { Inversión } \\
\text { Extranjera } \\
\text { Directa en } \\
\text { miles USD }\end{array}$ \\
\hline Ecuador & 6 & $22 \%$ & $\begin{array}{l}\text { C Altamente } \\
\text { Riesgoso }\end{array}$ & $48,90 \%$ & 19.122 & 2.406 \\
\hline Perú & 19 & $29 \%$ & $\begin{array}{l}\text { A4 Riesgo } \\
\text { Razonable }\end{array}$ & $63,30 \%$ & 44.039 & 6.719 \\
\hline Colombia & 15 & $35 \%$ & $\begin{array}{l}\text { A4 Riesgo } \\
\text { Razonable }\end{array}$ & $63,40 \%$ & 37.770 & 14.518 \\
\hline
\end{tabular}

Elaborado por: El autor

Fuente: (Ministerio de Comercio Exterior e Inversiones. Ecuador, 2018) (Ministerio de Comercio Exterior y Turismo. Perú, 2018), (Ministerio de Comerio, Industria y Turismo. Colombia, 2018), (OMC, 2018 b), (COFACE, 2017), (The Heritage Foundation , 2018), (Trade Map, 2018), (Proinversión Perú, 2018), (PROCOLOMBIA, 2018), (Banco Central del Ecuador, 2018), (CEPAL, 2017).

De acuerdo con la tabla, se han analizado variables pertinentes con la finalidad de dar una respuesta al por qué el Ecuador posee un desempeño comercial inferior al de Perú y Colombia posicionándose como un país proteccionista tomando como referencia al año 2017.

\section{Acuerdos comerciales vigentes}

Dentro de la variable acuerdos comerciales vigentes, se puede evidenciar que Colombia y Perú cuentan con 15 y 19 acuerdos respectivamente con países como: Estados Unidos, Japón, China, Corea, India, la Unión Europea, Latinoamérica, entre otros; viéndose como países aperturistas al comercio internacional, mientras que el Ecuador presenta solamente 6 acuerdos comerciales ratificados hasta la fecha, siendo los más representativos los mantenidos con la Unión Europea y la Comunidad Andina de Naciones; y acuerdos de alcance parcial con países de Latinoamérica como México, Chile y el MERCOSUR, demostrando un interés más focalizado en el comercio intrarregional, lo que provoca que Ecuador no alcance ni a la mitad de acuerdos comerciales que tienen sus vecinos más próximos (Ministerio de Comercio Exterior e Inversiones. Ecuador, 2018). 
Esta realidad coloca al Ecuador en una situación poco favorable al momento de competir, puesto que, los tres países son exportadores de productos agrícolas y de manufacturas con menor valor tecnológico, lo cual hace que los productos ecuatorianos sean más costosos que los de sus vecinos, ya que no gozan del mismo nivel preferencial arancelario y no arancelario que conceden los acuerdos comerciales regionales (Lundsgaare, Breung, \& Prakash, 2010).

Cabe mencionar que, mientras Colombia y Perú han buscado nuevos mercados en Asia, Norteamérica y Europa desde comienzos del nuevo milenio, el Ecuador apenas ha comenzado su acercamiento con la Unión Europea, en donde su Acuerdo de Asociación Económica está en vigencia desde enero del 2017. Igualmente, en el año 2018 Ecuador está viviendo un mayor acercamiento con importantes bloques como el EFTA (Ministerio de Comercio Exterior e Inversiones. Ecuador, 2017).

\section{Arancel consolidado}

Hace referencia al nivel máximo de arancel NMF que un país puede aplicar para una línea de producto determinada, este arancel es negociado en el marco de los acuerdos de la Organización Mundial del Comercio. Funciona como un techo en el cual los países miembros de la OMC negocian su máximo porcentaje de aplicación, el mismo que no podrá ser sobrepasado; los miembros consolidan los aranceles de acuerdo a su economía y nivel de apertura comercial. Cabe mencionar que los países de ingreso reciente a la OMC tienen un nivel inferior de consolidación arancelaria.

En el caso de los tres países analizados en la tabla, el país con un mayor promedio de consolidación es Colombia con un $35 \%$, seguido de Perú con un $29 \%$ y por último Ecuador con un $22 \%$, lo que quiere decir que Colombia y Perú tienen un mayor promedio de protección para determinados productos. En el caso de Colombia, existe mayor porcentaje de aranceles en productos como: carnes, derivados de la carne, lácteos y animales vivos; Perú tiende a proteger de mayor manera a productos como: maíz trigo, lácteos, arroz y azúcar y, por su parte Ecuador aplica un mayor porcentaje de arancel a las carnes, lácteos y arroz en su mayoría (OMC, 2018 b).

Dentro de este análisis, cabe recalcar que, el Ecuador tiende a aplicar aranceles elevados a las mercaderías importadas, pero en promedio su arancel consolidado es menor que el de Colombia y Perú. Este hecho, ubica a Ecuador como un país que se maneja con un promedio arancelario no tan elevado, razón por la cual, el país ha tenido que utilizar otras herramientas de protección como las salvaguardias, para controlar la balanza comercial, mientras que Perú y Colombia han traspasado esas barreras arancelarias, ratificando acuerdos comerciales preferenciales.

\section{Riesgo país}

Conociendo que el indicador riesgo país es muy utilizado por los inversionistas al momento de invertir en el exterior, se debiera conocer las razones del por qué ciertos países resultan ser más atractivos que otros.

En la evaluación del riesgo país para el año 2017, Ecuador se ubica como un país poco confiable al momento de invertir, principalmente por la desaceleración de la economía, restricciones arancelarias y no arancelarias al comercio exterior, inestabilidad política y déficit por cuenta corriente y balanza de pagos provenientes principalmente de los precios del petróleo.

En consecuencia, Ecuador se encuentra en la categoría de países riesgosos, siendo esta la quinta posición de las siete utilizadas para medir el riesgo país, mientras que, Colombia y Perú 
se muestran como países con riesgo razonable, ubicándose en la cuarta posición para medir el riesgo país (COFACE, 2017).

Bajo este contexto, Ecuador se está mostrando como un país con un entorno empresarial poco atractivo, con importantes problemas internos que tiene que ir resolviendo, para que de esa manera pueda implementar un verdadero cambio hacia el aperturismo comercial, de otra manera, no será capaz de competir con la confianza que han ido mostrando Perú y Colombia al inversionista extranjero.

\section{Índice de libertad económica}

Es la libertad que tienen los ciudadanos de un Estado para generar riqueza, mientras más alto sea el índice, mayor libertad económica presentan, siendo el 100\% el máximo porcentaje. Haciendo un análisis general de este indicador resaltan: Hong Kong, Singapur y Nueva Zelanda, las tres economías más libres del mundo. En Latinoamérica el primer clasificado es Chile, en el puesto 20, seguido de Uruguay en el 38.

Dentro de los países analizados, podemos destacar que Colombia y Perú se ubican en los puestos 42 y 43 respectivamente, con un 68,9\% y 68,7\%, ubicándose en la categoría de economías moderadamente libres. Por otro lado, el Ecuador presenta un nivel muy inferior de libertad económica ya que se encuentra en la categoría de países represivos ubicándose en el puesto 165 de 180 , con un 48,5\%.

Determinantes como: la apertura al libre mercado de capitales y a la inversión extranjera, control de la deuda pública, control del gasto público, aplicación de impuestos, fomento de un esquema de competencia para mejorar la productividad, definen si un país se miran con mayor o menor nivel de libertad económica (The Heritage Foundation , 2018).

Para Ecuador este es un escenario nada favorable, ya que se encuentra entre los países que menos libertad ofrecen a sus ciudadanos para generar riqueza y al tener un esquema jurídico en el que se debe otorgar al extranjero el mismo trato que se da a los nacionales, dejaría al Ecuador en una latente desventaja frente a Colombia y Perú.

\section{Exportaciones totales en miles USD}

Dentro de las exportaciones totales, se puede evidenciar otra desventaja para el Ecuador, en donde este país alcanza los 19 mil millones de dólares para el año 2017, mientras que, Colombia y Perú registran 44 mil y 37 mil millones de dólares cada uno; por otra parte, de este monto total de exportaciones, para el caso de Ecuador el $58 \%$ es representado por alimentos y manufacturas, asimismo con un $40 \%$ para Colombia y $37 \%$ para Perú, esto demuestra la dependencia que tienen los tres países a productos como el petróleo y minerales metalíferos, por lo que el precio de dichos productos determina el aumento o la caída de las exportaciones (Trade Map, 2018).

Las exportaciones totales enmarcan una debilidad del Ecuador al no poder llegar al mismo nivel de sus vecinos más próximos, sabiendo que la oferta exportable de los tres países es similar por concepto de su cercanía geográfica, cultural y económica, y con la imperativa necesidad de producir y exportar manufacturas con mayor valor agregado.

Países como: Estados Unidos, China, la Unión Europea y los miembros de la CAN, son los socios comerciales más importantes de los tres países, de ahí nace la evidente necesidad de concretar acuerdos comerciales con acceso libre a estos mercados. De esta reflexión se resalta el esfuerzo que han venido realizando Perú y Colombia para insertarse en la región Asia - Pacífico, por 
medio del Foro de Cooperación Económica Asia-Pacífico APEC, Alianza del Pacífico, Acuerdo Transpacífico de Cooperación Económica TPP, acuerdos que incluyen a importantes economías como, Estados Unidos, Japón, China, Australia, Corea del Sur, Canadá, entre otras (Direcon, 2018).

\section{Inversión extranjera directa}

Dentro de este indicador se puede evidenciar que a pesar de que Perú tiene un mayor nivel de exportaciones para el año 2017, Colombia duplica el monto de captación de IED para el mismo año. Perú registra 6.719 millones de dólares con principal participación en sectores como: minería, comunicaciones, servicios financieros y energía; los principales inversores en el Perú son: Chile, España, Estados Unidos y Reino Unido (ProinversiónPerú, 2018).

Para el caso de Colombia la IED llegó a 14.518 millones de dólares con principal participación en sectores como: comunicaciones, transportes, explotación de hidrocarburos y servicios financieros; los principales inversores en Colombia son: Estados Unidos, Reino Unido, España y Suiza (PROCOLOMBIA, 2018).

Para el caso de Ecuador se vuelve a repetir una tendencia de alejarse de sus vecinos con tan solo 2.406 millones de dólares captados para el 2017 con principal participación en sectores como: minas y canteras, y comercio e industria manufacturera, siendo sus principales inversores México, Canadá, China, España y Panamá.

Esta realidad demuestra que Ecuador está muy por debajo de sus vecinos más próximos, ubicándose en el séptimo país destinatario de inversión extranjera directa en Suramérica y siendo uno de los países que menos inversión captan en la Región (CEPAL, 2017).

\subsection{Análisis de percepción por entrevistas}

Por medio del análisis de percepción los informantes pudieron destacar información altamente relevante sobre la política comercial de Ecuador y su posición frente a Colombia y Perú, que complementa lo mencionado anteriormente en el presente trabajo de investigación.

\section{Una institución del sector público ecuatoriano a cargo del comercio exte- rior}

El sector público informa que el atraso que presenta Ecuador frente a sus vecinos más próximos está centrado principalmente en factores como: la devaluación del Peso colombiano y el Sol peruano, actividad que es imposible de realizar para el Ecuador, al no poseer moneda propia; además de los altos costos de logística y el lento desarrollo de procesos para mejorar la calidad de los productos de exportación.

En base a lo expuesto, el informante detalla que la mejor opción para el Ecuador no solo se debe enfocar a una apertura comercial que incluya diversos acuerdos comerciales con diferentes países y bloques regionales, sino también es necesario diversificar la oferta exportable del país con productos con valor agregado, ya que, existen acuerdos comerciales que tiene el Ecuador pero con partidas arancelarias que no están siendo usadas, así mismo la decisión de ratificar o no un acuerdo comercial debe nacer de un análisis costo - beneficio para el Ecuador, para que de esa manera se pueda aprovechar de las ventajas arancelarias y no arancelarias que brinda la apertura comercial. 
La percepción ubica al Ecuador como un país que quiere ser visibilizado ante el ojo de la comunidad internacional, dispuesto a negociar y abrirse camino hacia el incremento y diversificación de las exportaciones y mayor atracción de inversión extranjera directa (Anónimo, 2018).

\section{Una institución del sector privado ecuatoriano que participa y promueve el comercio exterior}

El sector privado acentúa que si bien la apertura de la política comercial del Ecuador se ha ido desarrollando desde el año 2017 con el cambio de gobierno, los efectos de ese cambio no se pueden percibir a gran escala aún, ya que el proceso del diseño, aplicación y evaluación de las políticas toma tiempo; sin embargo, manifiestan que la competitividad y la internacionalización superior que mantienen Perú y Colombia se debe a la temprana apertura comercial que presentaron esos países, en donde los acuerdos comerciales con socios estratégicos han sido clave para llevar sus productos a mercados internacionales y atraer inversión extranjera directa, mucho antes que Ecuador.

Bajo este mismo contexto, los informantes señalan que Ecuador se ve aun como un país poco competitivo y que su problema, no sólo se centra en su proteccionismo comercial, sino también por ser un mercado que carece de certeza jurídica, rigidez laboral y con altos costos de producción, por lo que es necesario mejorar los niveles de competitividad como país y así aprovechar de mejor manera los acuerdos comerciales (Robalino, 2018).

\section{Una ecuatoriana profesional en comercio exterior que reside en Colombia}

De acuerdo con la informante, el Ecuador presenta una desventaja puntual frente a Perú y en este caso Colombia, por el hecho de que los productos ecuatorianos no gozan de preferencias arancelarias las mismas que son otorgadas por los acuerdos comerciales, además señala que la industria ecuatoriana está teniendo un crecimiento lento a comparación de sus vecinos y que la política comercial del Ecuador es considerada como proteccionista.

La percepción puntualiza que la apertura comercial no dañaría la industria interna del Ecuador sino más bien, obligaría a los comerciantes ecuatorianos a mejorar la calidad y precio de sus productos y así poder competir con los productos importados (Donoso, 2018)

\section{Dos académicos y empresarios peruanos con conocimiento del mercado ecuatoriano}

Los informantes apuntan que Ecuador no ha tenido el mismo nivel en exportaciones tanto de bienes como servicios comparado con Colombia y con Perú, debido a que el Ecuador no posee una política comercial clara, ya que se ha percibido más proteccionismo que aperturista, además señalan que la falta de acuerdos comerciales ha vuelto relativamente lento el crecimiento de Ecuador a diferencia de los dos países objeto de investigación.

De igual manera, enfatizan que, por medio de una mayor apertura comercial, el Ecuador estaría obligado a mejorar la calidad de sus productos para ser más competitivo, ya que al no poseer moneda propia, este carece de la ventaja de ajustar su economía de acuerdo a los cambios monetarios mundiales.

En general, también resaltan la existencia de una alta intervención del Estado en diversos 
sectores de la economía, incluso en aquellos no estratégicos, limitando la inversión privada extranjera y nacional (Capcha, 2018), (Aguirre, 2018).

\section{Conclusiones}

Luego de la ejecución del presente análisis, se ha podido encontrar que el Ecuador no solo presenta un nivel de exportaciones más bajo a comparación de Perú y Colombia, pese a los esfuerzos enmarcados por aumentar y mejorar el nivel de dichas exportaciones bajo su actual legislación; sino que, las variables analizadas también ubican a la política comercial de este país como proteccionista, con una alta necesidad de aumentar la internacionalización de su producción y mejorar su imagen internacional.

El proteccionismo que muestra Ecuador ante la mirada de la comunidad internacional hace que el país pierda certidumbre jurídica para la atracción de capitales extranjeros, con un clima para hacer negocios poco favorable, en donde su escaso número de acuerdos comerciales en vigencia, su enfoque más ideológico hacia la Región (Latinoamérica) y la excesiva intervención del Estado, se convierten en determinantes para que la política comercial ecuatoriana no se desarrolle al mismo nivel que Colombia y Perú.

Por otro lado, Colombia y Perú países también analizados en el presente trabajo por su cercanía geográfica, cultural y económica con el Ecuador, se muestran como países con una política comercial aperturista, en donde los acuerdos comerciales vigentes que mantienen con socios estratégicos como: Estados Unidos, China, Japón, etc., y una mayor certidumbre para hacer negocios han sido determinantes para su actual desarrollo comercial, resultado de esto se puede apreciar en su nivel de exportaciones e inversión extranjera directa, siendo claramente, países más atractivos y confiables al momento de invertir.

La apertura comercial de Ecuador ha ido desarrollándose en los últimos años, teniendo como resultado la negociación de los acuerdos comerciales con la Unión Europea y con la Asociación Europea de Libre Comercio, con el fin de tener mayor competitividad y diversificar la oferta exportable, sin embargo, estos acuerdos tienen menos de dos y un año respectivamente, por lo que la imagen del proteccionismo ecuatoriano sigue vigente reflejándose tanto en las estadísticas, así como también en la percepción de informantes clave para el estudio de caso.

Finalmente, el Ecuador tiene que continuar e incrementar el trabajo para aplicar políticas, con el objetivo de otorgar certidumbre jurídica y así verse como un país con mayor libertad para hacer negocios y dejar de percibirse como un país proteccionista, asimismo tiene que seguir en la búsqueda de mayores relaciones económicas internacionales, para que de esa manera, no se quede atrás de sus vecinos más próximos y genere un mayor desarrollo comercial, ya que la política comercial debe mantenerse y trascender de acuerdo a las necesidades del país y no de acuerdo a ideologías de los gobiernos de turno. 


\section{Referencias bibliográficas}

- Banco Central del Ecuador. (2018). Índices de Inversión Extranjera Directa. Obtenido de https://www.bce.fin.ec/index.php/component/k2/item/298-inversi\%C3\%B3n-extranjera-directa

- Bayne, N., \& Woolcock, S. (2011). The new economic diplomacy. Decision-Making and Negociation in International Economic Relations. Londres: The London School of Economics and Political Science.

- Berg, A., \& Krueger, A. (2002). World Bank. Obtenido de https://www.imf.org/external/pubs/ft/ fandd/spa/2002/09/pdf/berg.pdf

- Berridge, G., \& James, A. (2001). A dictionary of diplomacy. Milan: Palgrave Macmillan.

- Bhagwati, J., \& Krueger, A. (1995). The Dangerous drift to Preferential Trade Agreements. Washington DC: American Enterprise Institute Press.

- BID. (2016). ¿Qué son los acuerdos comerciales y cuál es su importancia? Nuevas tendencias en los tratados comerciales en América Latina, 10-15.

- Capcha, J. (06 de 2018). ANÁLISIS EXPLORATORIO DE LA APERTURA COMERCIAL DEL ECUADOR FRENTE A PERÚ Y COLOMBIA.

- CEPAL. (2008). Indicadores de comercio exterior y política comercial: generalidadesmetodológicas e indicadores básicos . Obtenido de https://www.cepal.org/es/ publicaciones/3689-indicadores-comercio-exterior-politica-comercial

- CEPAL. (2011). Manual de comercio exterior y política comercial Nociones básicas, clasificaciones e indicadores de posición y dinamismo. Obtenido de https://repositorio.cepal. org/bitstream/handle/11362/3914/1/S2011090_es.pdf

- CEPAL. (2015). Panorama de la Inserción Internacional de América Latina y el Caribe. Obtenido de https://repositorio.cepal.org/bitstream/handle/11362/39010/S1501143_ es.pdf;jsessionid=2E9BEA73116DF98796A98343611F7FF3? sequence $=4$

- CEPAL. (2017). Comisión Económica para América Latina y el Caribe. Obtenido de http:// www.cepal.org/sites/default/files/publication/files/s1500146_es.pdf

- Chesnokova, T. (2014). Lobby interaction and trade policy. Moscow: Journal of Institutional and Theorical Economics.

- COFACE. (2017). For Safer Trade. Obtenido de Evaluación de Riesgo País: http://www. riesgopaiscoface.com/start/

- Cooper, R. (1987). Trade Policy as Foreign Policy. Cambridge: MIT Press.

- COPCI. (2010). Código Orgánico de la Producción Comercio e Inversiones.

- Corbo, V. (1985). Estudios Públicos, Chile. Obtenido de file://C:/Users/Adrian/Downloads/ Estrategias\%20para\%20el\%20Comercio\%20Exterior.pdf

- Direcon. (2018). Dirección General de Relaciones Económicas Internacionales, Chile. Obtenido de https://www.direcon.gob.cl/acuerdos-comerciales/

- Donoso, E. (06 de 2018). ANÁLISIS EXPLORATORIO DE LA APERTURA COMERCIAL DEL 


\section{ECUADOR FRENTE A PERÚ Y COLOMBIA.}

- Durán, J., Finot, A., \& LaFleur, M. (2010). División de Comercio. Obtenido de https://repositorio. cepal.org/bitstream/handle/11362/3829/1/lcw366.pdf

- Escribano, G. (2001). La interacción entre política económica y política exterior en la Unión Europea. Revista electrónica de estudios internacionales, 1-14.

- Gestión. (2017). Exportaciones sumarían US\$38,647 millones en el 2017. Obtenido de https:// gestion.pe/economia/adex-exportaciones-sumarian-us-38-647-millones-2017-124765

- Gibbs, M. (2007). POLÍTICA COMERCIAL. Obtenido de https://esa.un.org/techcoop/ documents/trade_spanish.pdf

- Gilpin, R. (1987). La Economía Política de las Relaciones Internacionaes. Buenos Aires: GEL Editores.

- Herrera, C. (2015). PROCESO DE INTEGRACIÓN DE AMÉRICA LATINA Y EL CARIBE. Ciencias Sociales 158, 169-180.

- Jaumotte, F., \& Spatafora, N. (2007). Asia Rising: A Sectoral Perspective. Obtenido de file:///C:/ Users/Adrian/Downloads/SSRN-id995630.pdf

- Kindleberger, C. P. (1986). International Public Goods without International Government. Washington DC: American Economic Review.

- Lifeder. (2018). Obtenido de https://www.lifeder.com/entrevista-de-investigacion/

- Loko, B., \& Diouf, M. A. (2009). Revisiting the Determinants of Productivity. Obtenido de https:// www.imf.org/external/pubs/ft/wp/2009/wp09225.pdf

- Lundsgaare, E., Breung, C., \& Prakash, A. (2010). Instrumental Philantropy: trade and the allocation of foreign aid. Canadian journal of political science, 733-761.

- Milner, H. (1999). The political economy of international trade. Annual review of political science, 91-114.

- Ministerio de Comercio Exterior e Inversiones. Ecuador. (2017). Rumbo al Acuerdo con el EFTA. Obtenido de https://www.comercioexterior.gob.ec/ecuador-apunta-al-acuerdo-comercial-efta/

- Ministerio de Comercio Exterior e Inversiones. Ecuador. (2018). Acuerdos Comerciales del Ecuador. Obtenido de https://www.comercioexterior.gob.ec/acuerdos-comerciales-3/

- Ministerio de Comercio Exterior y Turismo. Perú. (2018). Acuerdos comerciales vigentes. Obtenido de http://www.acuerdoscomerciales.gob.pe/

- Ministerio de Comerio, Industria y Turismo. Colombia. (2018). Acuerdos comerciales vigentes. Obtenido de http://www.tlc.gov.co/

- Montaño, C. (2010). Ecuador y la integración: una revisión a la posición oficial. Foro Revista de Derecho, 89-92.

- OMC. (2012). Órgano de Examen de las Políticas Comerciales . Obtenido de file://C:/Users/ Adrian/Downloads/G254.pdf

- OMC. (2018 b). Arancel Consolidado. Obtenido de https://www.wto.org/spanish/thewto_s/ 
countries_s/peru_s.htm

- OMC. (2018 c). GLOSARIO DE TÉRMINOS. Obtenido de https://www.wto.org/spanish/ thewto_s/glossary_s/mfn_tariff_s.htm

- Panezi, M. (2016). THE WTO AND THE SPAGHETTI BOWL OF FREE TRADE AGREEMENTS FOUR PROPOSALS FOR MOVING FORWARD. Policy Brief 87, 3.

- PROCOLOMBIA. (2018). Inversión Extranjera Directa. Obtenido de http://www. inviertaencolombia.com.co/noticias/1124-los-paises-con-mayor-inversion-extranjera-encolombia.html

- Proinversión-Perú. (2018). Obtenido de http://www.investinperu.pe/modulos/JER/ PlantillaStandard. aspx ?are $=0$ \&prf $=0$ \&jer $=5652$

- Reuvers, S. (2012). Research on commercial diplomacy: review and implications. Twente: Faculty of Managment and Gobernance, University Twente.

- Robalino, A. (06 de 2018). ANÁLISIS EXPLORATORIO DE LA APERTURA COMERCIAL DEL ECUADOR FRENTE A PERÚ Y COLOMBIA.

- Rodrik, D. (1994). What Does the Political Economy Literature on Trade Policy (Not) Tell Us That We Ought To Know? London: National Bureau of Economic Research.

- The Heritage Foundation . (2018). INDEX OF ECONOMIC FREEDOM. Obtenido de http:// www.iberglobal.com/files/2018/heritage_2018_highlights.pdf

- Torres, D., \& Gilles, E. (2013). Análisis de la política comercia ly su impacto en las exportaciones industriales colombianas (1990-2011). Obtenido de https://www.utadeo.edu.co/sites/tadeo/ files/node/publication/field_attached_file/pdf-_analisis_de_la_politica_comercial_-_pag-_0910-15.pdf

- Trade Map. (2018). Estadísticas del comercio para el desarrolo internacional de las empresas. Obtenido de https://www.trademap.org/Index.aspx

- UN. (2015). Obtenido de http://www.un.org/es/millenniumgoals/ 
